\title{
Assessing Vulnerability to Chronic Undernutrition among Under-Five Children in Egypt: Contextual Determinants of an Individual Consequence
}

\author{
Sumit Mazumdar \\ Institute for Human Development, 3rd Floor, NIDM Building, IIPA Campus, IP Estate, Mahatma Gandhi Road, \\ New Delhi 110002, India \\ Correspondence should be addressed to Sumit Mazumdar, mazumdarsumit@yahoo.com
}

Received 2 November 2011; Revised 21 March 2012; Accepted 1 April 2012

Academic Editor: Abbas Bhuiya

Copyright () 2012 Sumit Mazumdar. This is an open access article distributed under the Creative Commons Attribution License, which permits unrestricted use, distribution, and reproduction in any medium, provided the original work is properly cited.

Nutritional outcomes remain an important development indicator and reflect a household's vulnerability to improved quality of life. Drawing upon recent household survey data from Egypt, this paper applies hierarchical models to test the effect of contextual factors on chronic undernutrition among under-five children and identifies the demographic and socioeconomic characteristics that underscore such vulnerability. Results indicate considerable neighborhood effects influencing a household's nutritional choices. However, no significant effect could be identified for mother's education and women's decision-making power, but a clear positive association is evident between nutritional status and better health service utilization as well as child care and feeding practices. Focused intervention strategies need to augment household level behavioral change for these identified factors and supplement such individual efforts with targeted strategies aimed at vulnerable Egyptian communities to reduce child undernutrition.

\section{Introduction}

Hunger and nutritional failure signify both the cause as well as the consequence of a household's vulnerability to economic shocks, chronic and transient, and an important indicator of food insecurity, poverty, and deprivation of wellbeing. Assessment and understanding of the phenomenon of nutritional deprivation is crucial for gaining insights into vulnerability; it can be in identifying the causative factors and their pathways of influencing household food security. Furthermore, being a quantifiable outcome, objective indicators of nutritional failure can be decomposed to observe the relative influence of sociocultural, economic, communityspecific, and geographical vulnerabilities, which aids in prioritizing corrective intervention programs. Conventional vulnerability analyses has been predominantly focused on the production and availability of grain staples at the expense of other indicators, such as lack of access to health services, nutritional status, cultural practices, and gender inequality.
Such analyses failed to identify which population groups fell at relatively greater risk, and the underlying reasons.

This paper concentrates on child malnutrition, owing to its sublime importance towards development goals and future economic impact. Malnourishment during the early years can contribute to the prospective vulnerability of a household and can jeopardize the possibility of moving out of poverty traps. We examine relative vulnerability across households and individuals towards adverse nutritional outcomes, from the basic premise that these proximal determinants act in unison to threaten household food security, thereby applying constraints on adequate nutritional requirements among children. We seek to identify the contextual correlates of malnutrition and understand the relative risk and vulnerability to suffer from adverse nutritional outcomes. We focus on Egypt and present some descriptive statistics from secondary sources on the Arab world, but the results are expected to be significantly robust for other developing nations as well. 
FAO/FIVIMS framework: linkages between the overall development context,

the food economy, households, and individual measures of well-being

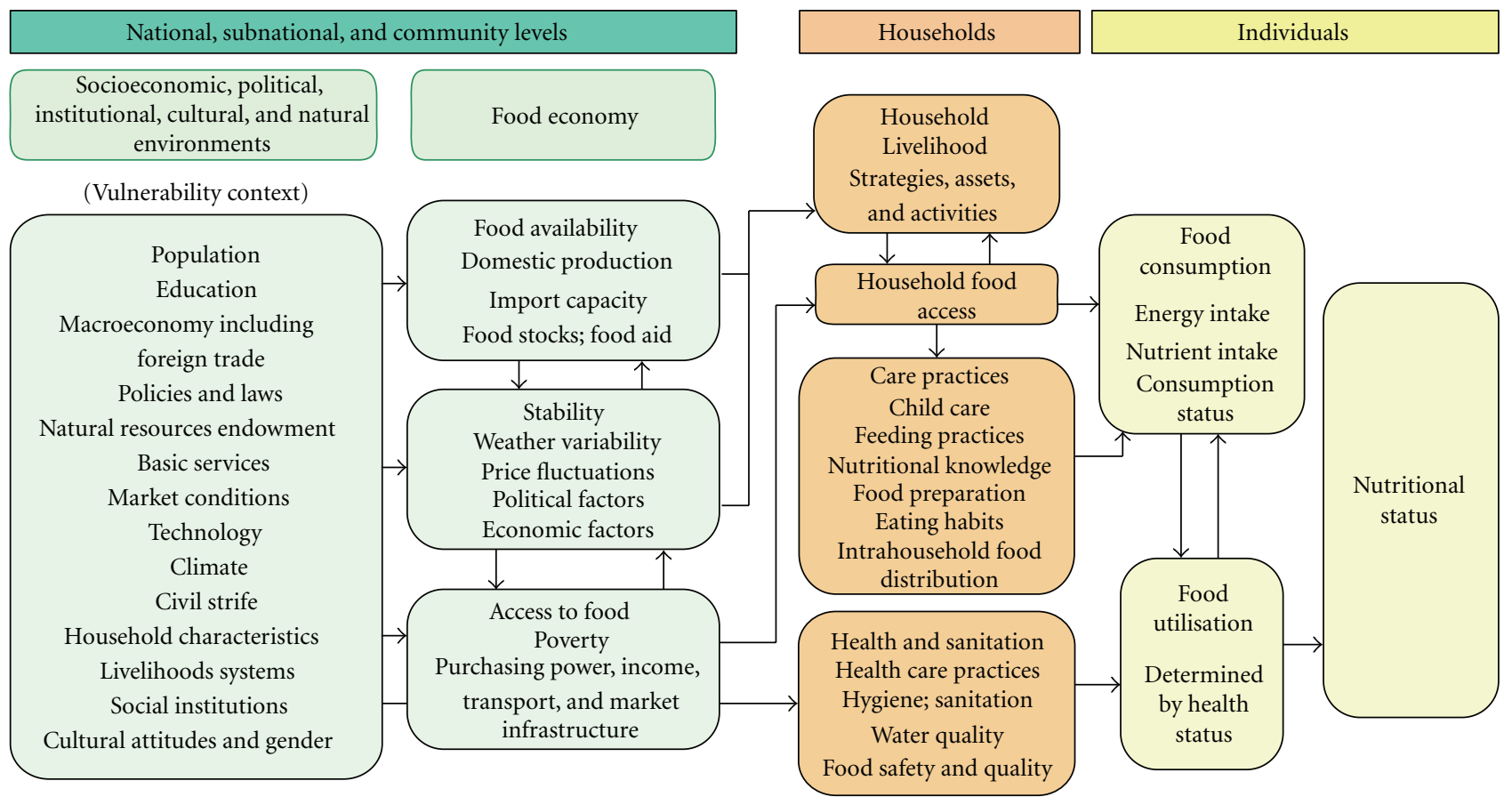

FIGURE 1: Conceptual framework of vulnerability and nutritional status. Source: http://www.fivims.org/.

Egypt is a low-income, food-deficit country, with considerable poverty, and regional pockets of high levels of food insecurity and malnutrition. According to the latest available DHS data for Egypt [1], there is considerable level of chronic malnutrition among Egyptian children. Overall, $29 \%$ of children under age five are stunted (short for age), with 14\% severely stunted, and though there has been a declining trend, stark socioeconomic differentials have been observed in the distribution of malnutrition in Egypt [1]. High prevalence of stunting among pre-school children and considerable regional variations has also been observed by a number of studies [2]. Although wasting (thin for age) is moderate (in the range of $5-10 \%$ ), yet this indicates prevalence of acute nutritional shortfalls, most likely to be concentrated among the vulnerable population groups (cited in [2]).

\subsection{Conceptual Framework of Vulnerability and Nutritional} Outcomes. Standard conceptual frameworks used in conventional vulnerability assessment and mapping have not been much applied to DHS data, primarily due to the paucity of adequate data on consumption and a money-metric of economic status. However, the wealth of information on other proximate determinants of child nutritional outcomes at the household level in the DHS datasets allows us to examine vulnerability to chronic and acute nutritional deprivation beyond the direct causality between household food security and nutritional status.

The framework for vulnerability assessment depicted above has been proposed by FAO as a standard theoretical underpinning for identifying the vulnerable allowing for the effects of proximal and intermediate correlates. Although suited more for macrolevel national analyses, testing the same using unit record household survey data is largely limited by dearth of information at the macronational/subnational level. Additionally, econometric considerations of pooling macrolevel observations across cross-sectional survey units (i.e., households and/or individuals) are fraught with problems too. In view of the above, we have laid out a simpler analytical framework (Figure 2) that rests on the conceptualization of vulnerability to long-term nutritional shocks illustrated in Figure 1. In Figure 2, which draws upon established frameworks for analyzing determinants of undernutrition among children (the commonest starting point has been the framework provided by UNICEF; see [3]), the proximal and intermediate determinants of undernutrition have been laid out, isolating factors operating at the community (or macrolevel), household, maternal, and childlevel covariates. We return to explain the variables used to operationalize the framework using the EDHS data in the next section.

\section{Data and Methods}

We use data from the latest available rounds of the Egyptian Demographic and Health Survey [1], which provides information on anthropometric indicators (height-for-age, weight-for-age, and weight-for-height) of children under age five. We employ the standard practice of considering the standardized $z$-scores of deviations from the reference 


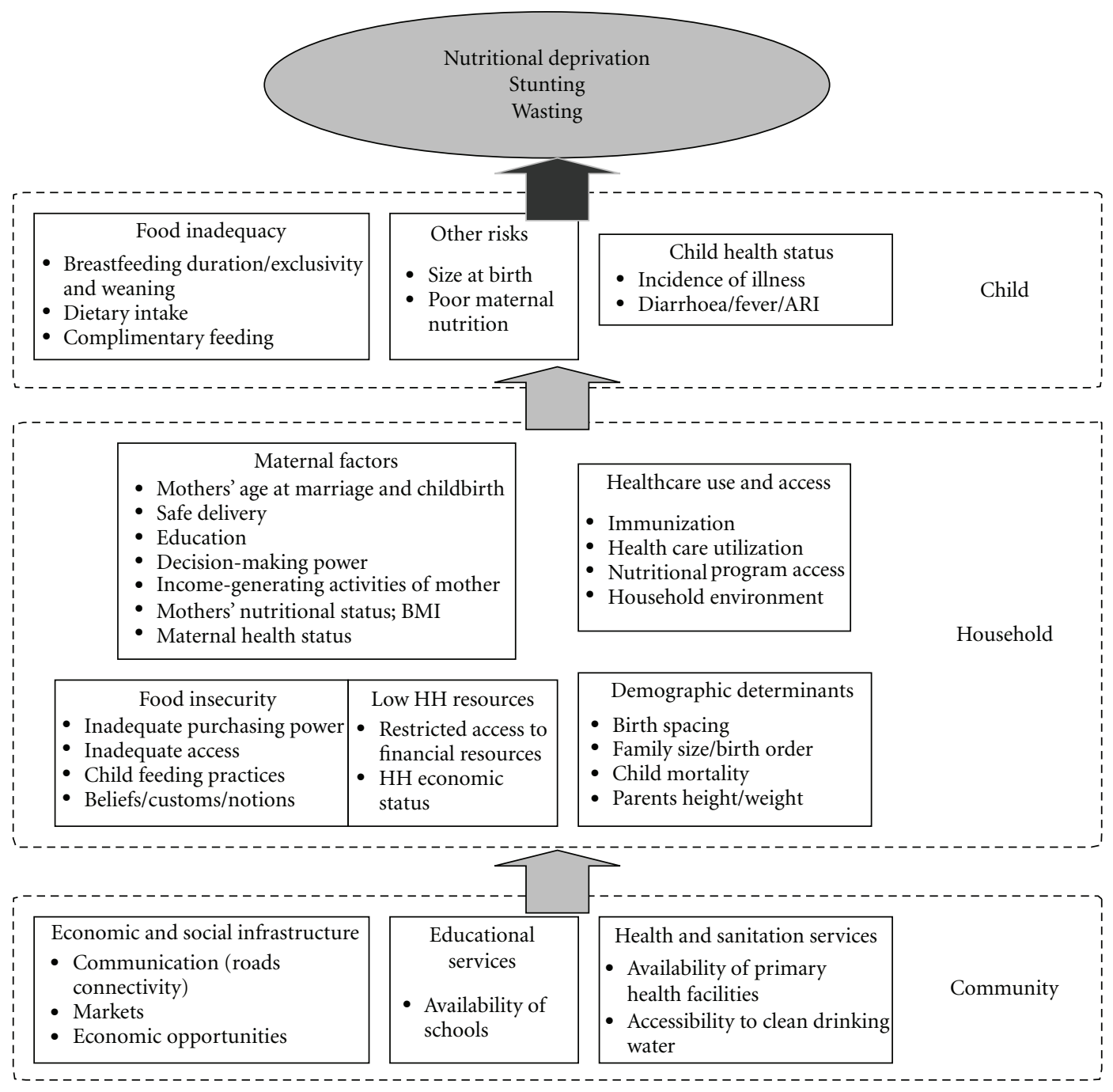

FIgURE 2: An analytical formulation of vulnerability to child nutritional outcomes at community, household, and individual levels.

population (for details please refer to [1]) for these anthropometric indices. In the absence of a formal "income" or "consumption expenditure" variable in the DHS, we rely on the household asset-based wealth index scores provided as a proxy for economic status.

To address the study objectives, we employ alternative econometric techniques. Initiating from an OLS regression of height-for-age (HAZ) scores on selected proximal and intervening parameters (following the analytical framework illustrated below), we move towards multilevel models allowing for cluster level random effects. The multilevel approach allows for possible correlation in undernutrition risks between children by including in the model a community/household-specific random effect. The outcome variable of interest in the OLS specification is the standardized $z$-scores of HAZ separately measured as deviations from the WHONCHS reference population [1]. Due to the hierarchical nature of the data, a nested model is used, where the child is nested within the mother, which in turn is nested within the household and the community (PSU) variable.
The primary motivation for a multilevel analysis stems from the hierarchically clustered nature of the EDHS data. Where children are nested into mothers, mothers are nested into households, households are into PSUs, and PSUs into regions. Hence, factors affecting health outcomes in general and child nutritional status in particular arise from different levels of aggregation. Apart from individual demographic and health attributes (e.g., age, gender, birth order, size at birth, etc.) which are independently determined for every children, siblings share certain common characteristics of the mother and the household (mother's education and household economic status for e.g.) and children from a particular community or village have in common community level factors such as availability of health facilities and outcomes, it can be reasonably asserted that unobserved heterogeneity in the outcome variable is also correlated at the cluster levels [4-7]. This amounts to an estimation problem employing conventional OLS estimators.

The classical OLS estimator is equally efficient as the maximum likelihood estimators only when the community 
level covariates, and the household level covariates are uncorrelated with the individual and maternal effects covariates [8]. However, a consequence of clustering as stated above is that observations within a cluster (household, community, and/or region) may be more homogenous than observations chosen at random, thus violating the assumption of independent observations; the classical assumptions of OLS estimators.

Researchers have adopted fixed effects models to estimate nutrition models and control for unobservable variables at the cluster level, which leads to the difficulty that if the fixed effect is differenced away, then the effect of those variables that does not vary in a cluster will be lost in the estimation process [5]. The variance-component model correct for the problem of correlated observations in a cluster, by introducing a random effect at each cluster. In other words, subjects within the same cluster are allowed to have a shared random intercept. Thus, we have

$$
z_{i j k}=\beta^{\prime} x_{i j k}+\delta_{i}+\mu_{i j}+\varepsilon_{i j k}
$$

where $z_{i j k}$ is the height-for-age $z$-score for the $k$ th child from the $j$ th household in the $i$ th community (any additional level, such as $l$ th state can be introduced likewise). $\beta$ is a vector of regression coefficients corresponding to the effects of fixed covariates $x_{i j k}$, which are the observed characteristics of the child, the household and the community, $\mu_{i j}$ is a random community effect denoting the deviation of community $i$ 's mean $z$-score from the grand mean, $\mu_{i j}$ is a random household effect that represents deviation of household $i j$ 's mean $\mathrm{z}$-score from the $i$ th community mean, and $\varepsilon_{i j k}$ is an individual error that represents deviation of the child $i j k$ 's $z$-score from the mean of household $i j$. The error terms $\delta_{i}, \mu_{i j}$, and $\varepsilon_{i j k}$ are assumed to be normally distributed with zero mean and variances $\sigma_{c}^{2}, \sigma_{h}^{2}$, and $\sigma_{i}^{2}$, respectively. As per our arguments above, these terms are nonzero and estimated by variance components models. To the extent that the greater homogeneity of within-cluster observations is not explained by the observed covariates, $\sigma_{c}^{2}$ and $\sigma_{h}^{2}$, will be larger [4]. To evaluate the appropriateness of the multilevel models, we test whether the variances of the random part are different from zero over households and communities. The resulting estimates from the models can be used to assess the intraclass correlation (ICC), that is, the extent to which child undernutrition is correlated within households and communities, before and after we have accounted for the observed effects of covariates $x_{i j k}$. A significantly different ICC (the ICC coefficient describes the proportion of variation that is attributable to the higher level source of variation. The correlations between the anthropometric outcomes of children in the same community and in the same family are respectively: $\varrho_{c}=\sigma_{c}^{2} /\left(\sigma_{c}^{2}+\sigma_{h}^{2}+\sigma_{i}^{2}\right)$ and $\varrho_{h}=$ $\left(\sigma_{c}^{2}+\sigma_{h}^{2}\right) /\left(\sigma_{c}^{2}+\sigma_{h}^{2}+\sigma_{i}^{2}\right)$ from zero suggests appropriateness of random effect models [5]. Following this, the total variability in the individual height-for-age $z$ scores can be divided into its three components: variance among children within households, households within communities, and communities. By including covariates at each level, the variance components models allow to examine the extent to which observed differences in the anthropometric scores are attributable to factors operating at each level.

The variance components model described above introduces a random intercept at each level or cluster. If additionally, we consider the effect of certain covariates to vary across the clusters (e.g., differential impact of household socioeconomic status, mother's education across households, and/or communities), we need to introduce a random effect for the slopes as well, leading to a random coefficients model. Under these assumptions, the covariances of the disturbances, and therefore the total variance at each level depend on the values of the predictors [4].

For the second objective, identifying the relative risk and vulnerability to suffer from both acute and chronic nutritional failure, linking individual consequences to contextual determinants of nutritional vulnerability requires a different analytical specification. Allowing for the cluster-level random effects, random-effect logit specifications of regression models were introduced, with dichotomous variables of anthropometric status as dependent variables. Occurrence of chronic undernutrition (using $z$-scores for HAZ) was regressed upon the earlier model covariates. Parsimonious model specifications were tested with introducing model covariates in stages, and changes in the model fit were observed through log-likelihood values to decide on the optimal model. All analysis were carried out using the STATA (release 9), employing the xtmixed and xtlogit routines for the multilevel analysis.

\section{Results and Discussion}

\subsection{Levels and Trends of Child Undernutrition in Egypt.} The Egyptian Demographic and Health Surveys (EDHSs) are an important source for monitoring the undernutrition problem among Egyptian children, and provide fairly detailed information about the background characteristics of the undernourished children, which helps in identifying the possible risk factors as well. Undernutrition in young children is most commonly measured in terms of stunting (low height for age), wasting (low weight for height), and underweight (low weight for age). These indices are compared against an international reference population. Children whose measurements fall below $-2 z$-scores of the reference population median are considered undernourished, that is, to have stunting, wasting, or to be underweight. Those children with measurements below $-3 z$-scores are considered to be severely undernourished. For the EDHS 2008 , standardized $z$-scores were provided based on a new international reference population released by $\mathrm{WHO}$ in April 2006 [9, 10]. Thus, while examining the trend in child undernutrition over the years, we have presented the estimates using the earlier standard (i.e., NCHS reference population) in Figure 3(a), and using the revised WHO reference population (Figure $3(\mathrm{~b})$ ).

As seen from the figures above, Egypt has witnessed mixed experience in child malnutrition over the past decade and half. Both for stunting as well as wasting, denoting long-term and acute nutritional deprivation, respectively, 


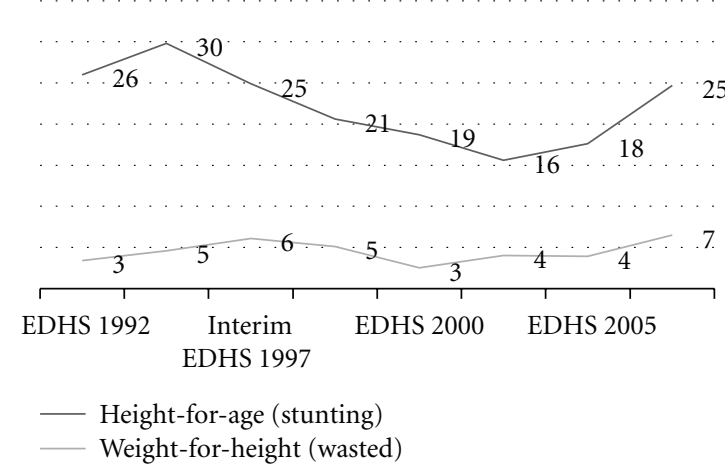

(a)

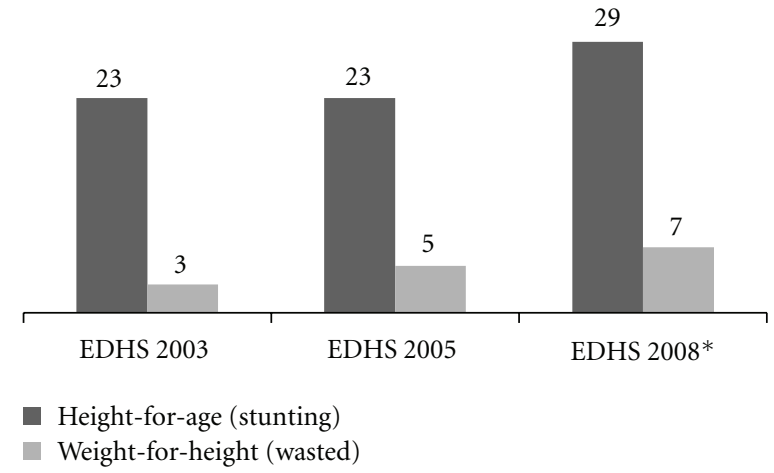

(b)

FIGURE 3: (a) trends in child malnutrition in Egypt (using NCHS reference population): 1992-2008 and (b) trends in child malnutrition in Egypt (using revised WHO reference population): 2003-2008.

prevalence has declined steadily for about a decade (19952003). However, a reverse trend is witnessed since 2003 (for $[1,11]$ ), with a visible increasing trend (Figure 3(a)). Similar trend is also observed while using the revised WHO reference population (Figure 3(b)). Average stunting among under-five children in Egypt was almost constant between 2003 and 2005, but had witnessed a spurt then on, with an increase of about six \% age points in the ensuing period. A temporary (and insignificant) rise in child malnutrition (or any other demographic rates and ratios) based on household survey data is understandable, and researchers have attributed such increases to better data quality, and in the present instance, improved means of measuring children's heights and better reporting of ages. However, an explanation for increasing trend observed since 2003, this does not explain the considerable increase in average stunting between 2005 and 2008 for obvious reasons (nonsampling errors in estimation can be reasonably expected to be stable over such shorter span of time). The EDHS quotes findings of Geerlings and others [12] in support of the hypothesis that large-scale culling of poultry in the wake of the outbreak of Avian influenza of 2006 in Egypt, might have reduced supply of chicken and eggs considerably to the households having a bearing on nutritional status, besides putting strain on household financial resources as poultry sales accounted for nearly half the incomes of Egyptian households prior to 2006 (Geerlings et al. 2006, cited in [1]). To what extent such transient shocks can affect an index which is more amenable to long-term shocks and vulnerabilities, is an important research issue in its own capacity and deserves further investigation, which is beyond the scope of the present paper.

As in other developing countries the incidence of longterm undernutrition among children in Egypt indicates significant extent of clustering across demographic, sociocultural and economic subsets of the population. About 29\% of the children under-five years of age in Egypt suffer from moderate long-term undernutrition and about 14\% from severe forms of it [1]. Marked socioeconomic differentials in average stunting exist in Egypt with considerably higher incidence in rural areas (30\%) compared to the urban areas (27\%). Regional differentials appear to be one of the major sources of the absolute heterogeneity, with considerable interregional variations, varying from $23 \%$ in Urban Governorates to $38 \%$ in Lower Egypt. Interestingly, and deviating from established patterns visible otherwise across the developing world, no systematic differentials are observed with respect to household economic status and mother's education, which are among the strongest predictors of child undernutrition. For mother's education, although no significant association could be established between broad categories of education and average stunting, a marginally higher proportion children of illiterate mothers (29\%) suffer from stunting compared to those with some schooling (27\%, $P$ value of chi-square $=0.07$ ) (summary results are available in the published reports of EDHS 2008 (please refer to the end of the text). Further computations are available from the author on request). But even such association is not visible using truncated categories of economic status (poor, middle, and rich on the basis of DHS wealth quintiles). Similarly mother's employment also does not reveal any significant association with average stunting. We review such deviant association in the multivariate analysis to follow while controlling for other proximate determinants in the hierarchical framework.

\subsection{Determinants of Long-Term Undernutrition among Chil-} dren in Egypt. There is well-documented evidence in literature citing the different correlates of child undernutrition in developing countries (e.g., [13-17]). The analytical framework we have presented earlier draws on the empirical findings of multivariate models used to identify correlates of child malnutrition. Being primarily focused on longterm nutritional deprivation, we concentrate on the analysis of the determinants of same, using standardized heightfor-age $z$-scores as the dependant variable (a negative transformation for easier interpretation) in the regressions. The explanatory variables have been selected guided by the analytical framework (Figure 2).

Child-level variables include size of the child at birth, birth order, and breastfeeding duration in months, apart from the conventional variables for age and sex of the child. Variables such as morbidity experiences of the child and 
TABLE 1: Average stunting (height-for-age) and wasting (weight-for-height) for countries in MENA region.

\begin{tabular}{|c|c|c|c|c|c|}
\hline \multirow[b]{2}{*}{ Country } & \multicolumn{2}{|c|}{ Wasting (Weight-for-Height) } & \multicolumn{2}{|c|}{ Stunting (height-for-age) } & \multirow{2}{*}{ Year } \\
\hline & $\begin{array}{c}\text { Below }-2 \\
\text { SD }\end{array}$ & $\begin{array}{c}\text { Below -3 } \\
\text { SD }\end{array}$ & $\begin{array}{c}\text { Below }-2 \\
\text { SD }\end{array}$ & $\begin{array}{c}\text { Below }-3 \\
\text { SD }\end{array}$ & \\
\hline Algeria & 9.6 & 5.1 & 23.3 & 10.8 & 2002 \\
\hline Bahrain & 5.3 & 0.3 & 9.7 & 2.7 & 1995 \\
\hline Egypt & 5.3 & 2.5 & 23.8 & 10.3 & 2005 \\
\hline Iran & 4.9 & 0.9 & 15.4 & 3.8 & 1988 \\
\hline Iraq & 6.6 & 2.4 & 28.3 & 9.4 & 2000 \\
\hline Jordan & 2.5 & 0.8 & 12 & 2.6 & 2002 \\
\hline Kuwait & 1.2 & 0.1 & 3.2 & 0.6 & 1996-97 \\
\hline Lebanon & 1.2 & 0.6 & 2.8 & 0.4 & 1996 \\
\hline Libya & 3.7 & N/A & 20.7 & N/A & 1995 \\
\hline Morocco & 10.8 & 5 & 23.1 & 9.8 & 2003-04 \\
\hline Oman & 7.3 & 1.1 & 12.9 & 2.4 & 1999 \\
\hline Qatar & 5.5 & N/A & 8.1 & N/A & 1995 \\
\hline Saudi Arabia & 11.8 & 4.5 & 9.3 & 2.6 & 2004-05 \\
\hline Sudan & 17.8 & 7.2 & 47.6 & 27.7 & 2000 \\
\hline Syria & 39 & 10.3 & 28.6 & 15.7 & 2006 \\
\hline Tunisia* & 4.4 & 1 & 20.3 & 7.5 & 2000 \\
\hline Yemen & 15.2 & 6.3 & 57.7 & 35.8 & 2003 \\
\hline
\end{tabular}

immunization status had to be left out due to the skewed distribution (more than 98\% children were either partly or fully immunized) in the household data. Maternal-level covariates are conceptualized as being nested within the household-level variables (in EDHS less than 10\% of the women shared the same household). These variables include mother's level of education, age at childbirth, nutritional status in terms of BMI, and place of delivery of the child (initial selection of mother-level covariates also included employment, but was later dropped due to collinearity with the decision-making index). Owing to the empirical evidences of influence of women's status and decisionmaking power on the long-term nutritional status of children [18], a composite index of decision-making power of the women was employed (women's decision-making index was estimated by principal component analysis. The indicator combines whether woman works for cash income, percentage age difference between woman and husband, woman's age at marriage and educational difference, in years, between woman and spouse, normalized to a scale of 0-100 [18]). Place of delivery, apart from denoting improved receipt of post- and ante-natal care by the women, also proxies the extension of healthcare service delivery and maternal and child health intervention programme outreach in general, which has a definite bearing on overall health of the child including nutritional status. For similar reasons, a composite index of healthcare utilization combining experiences of seeking post- and ante-natal care and medical treatment in the case of childhood illnesses was also included.

Sociocultural covariates also play a significant role in determining child nutritional status that acts through intermediate variables, namely, infant and child feeding practices and notions [19]. As such, a composite index of infant and child feeding practices developed by Ruel and Menon has been employed [19]. Household financial resources and economic status, an important predictor is included in the model as well. Following the methodology suggested by Rutstein and Johnson [20], a wealth index variable has been made available in the EDHS data, which we transformed into wealth index quartiles and used as proxy for economic standards.

A group of demographic variables such as birth-spacing and birth order of the child have also been incorporated in the models. In the absence of alternative community-level or macro determinants, we have in the models variables for place of residence (urban/rural), and geographic regions. To proxy for the availability and accessibility of public welfare programmes having a bearing on health status, we include two variables: one denoting the perception of the respondent on the distance from the nearest health facility and piped water connection to the household (Table 1).

3.3. Random-Effects Multilevel Models. As mentioned before, the EDHS data used for this study is hierarchically clustered alike other DHS datasets. Our multilevel models are based on observations on 8505 children (deleting dead children and currently pregnant mothers as well as cases with unreasonable observations/flagged cases) from 6191 households distributed in 1214 clusters (PSUs). Inclusion of a separate level for mothers was considered in spite of a low mother: household ratio (with 6483 mothers) due to a lower " $N$." Additionally, it was felt that owing to the visible regional pattern and heterogeneity in health outcome, inclusion of a separate level (or a random intercept) for regions would be insightful. Thus, the model had four nested levels: 8505 children from 6483 mothers belonging 
to 6191 households nested within 1214 communities, which in turn is nested within the 6 regions. We have used five alternative model specifications: model 1 is the conventional OLS regression model using all covariates; Models 2-5 are the fixed and random effect multilevel models. Model 2 is a null model; model 3 introduces a fixed-effect at the level of the households, while model 4 tests for a similar random effect at the household level. Model 5 is the full-multilevel model with all model covariates at respective levels of the clustered data. The parameter estimates of OLS and other multilevel models are presented in Table 2.

As seen from the results of the OLS model, better nutritional outcomes, indicating higher height-for-age values is significantly associated with being female and among children of larger than average size at birth. Mothers, who had given birth at higher ages, have normal BMI values (suggesting better maternal nutritional status) and had given birth at institutions have their children enjoying better longterm nutritional status. Apparently, an inverse association is observed between duration of breastfeeding and long-term nutritional status, with longer (more than 6 months) of breastfeeding associated with increased incidence of stunting. However, this result should be interpreted cautiously. Evidence in literature suggest a nonlinear effect of breastfeeding duration and nutritional status, with prolonged breastfeeding beyond six months of the child's age signaling delayed onset of weaning (most likely due to household food availability and/or cultural notions about infant and child care feeding practices), which in turn may lead to nutritional deprivation and usher chronic undernutrition. In Egypt, as well, the pattern can be identified. From the adjoining figure (Figure 4), it is visible that average stunting is more pronounced among children who are breastfed beyond six months $(30 \%)$ compared to those of less than six months of age (19\%). Similarly, for children who are currently being breastfed, those of younger age (less than/equal six months) are visibly less stunted than those of higher ages and still being breastfed.

A clear linkage of economic status with child undernutrition is evident; children from the poorer economic classes share a higher proportionate burden of undernutrition as seen from the regression coefficients on the wealth index variable. Stunting is also lower among children from households with better levels of health services utilization. Along similar lines, children enjoying better infant feeding and care practices are less stunted, which taken together suggests a positive association of better health-care seeking and child care behavior with undernutrition risks.

In model 3, we introduce a fixed-effect term at the household level, after trying with regional, and governorates as well, which were ruled out on account of insignificant model variances being explained. The estimate of $\rho$ (61.2) indicated that considerable variances are being explained at the household level. The F-test following the regression indicates that household level effects are significant and it would be inappropriate to employ an OLS specification of the regression model (model 1). Nevertheless, as seen in Table 3, the coefficients of the model covariates are not significantly changed under the present form (fixed-effect

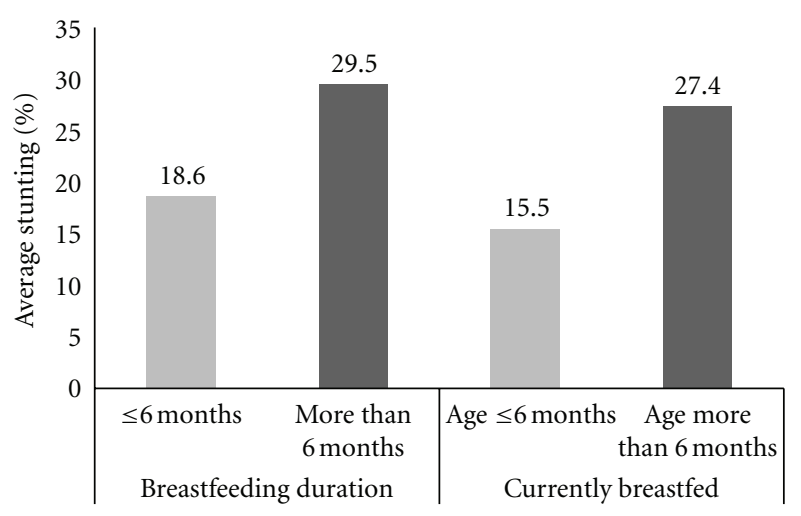

FIGURE 4: Association of breastfeeding duration with stunting.

model), so the inferences remain largely intact. However, two changes are noticed. Firstly, women's decision making emerges as of having a desired, positive association with child undernutrition - mothers with better decision making power seem to take better care of their children in terms of feeding practices and utilizing required healthcare services (which also possibly explains the last two variables losing their significance in the fixed-effects specification). Secondly, the economic gradient in child stunting intensifies significantly.

To further test the viability of a household-level fixedeffect term, we alternatively employ a similar randomeffects term at the household level (model 4). However, the random-effect specification though reported for indicative comparison, was found to be of little added value since, a Hausman test to compare the applicability of the fixed and random-effect models (models 3 and 4) rejects the null hypothesis that the random-effects estimator is consistent [21]. The household-level individual effects do appear to be correlated with the regressors.

None of the model formulations employed above have been corrected for the inherent clustering of the EDHS data we have used. As discussed earlier, and confirmed by the results of the Hausman test, it is naive to reject the intracluster correlation between observations (for the regressors employed), which calls for the multilevel framework. In model 5, we estimate a variance component form of the standard multilevel framework allowing for a four-level cluster effect, namely, region level, community (cluster)level, household level, and mother level. Accounting for the hierarchical nesting of the observations comes at a cost though; some variables lose the statistical significance in their association with stunting. However, the gradients of economic status, women's decision making, duration of breastfeeding, and healthcare utilization persists. Additional interesting implications of the multilevel models emerge distinctly from an examination of the cluster effects.

Firstly, observations among households belonging to particular clusters are strongly correlated, a fact that reconfirms the inapplicability of classical OLS regression forms. Second and most importantly, a significant extent of the observed variance in undernutrition levels among children 
Table 2: Determinants of chronic child undernutrition, Egypt 2008.

\begin{tabular}{|c|c|c|c|c|c|}
\hline Predictors & Model 1 & Model 2 & Model 3 & Model 4 & Model 5 \\
\hline \multicolumn{6}{|l|}{ Child-level covariates } \\
\hline Age of the child (in months) & 0.001 & & $-0.022^{* * *}$ & $-0.013^{* * *}$ & $-0.013^{* * *}$ \\
\hline Sex of the child (base: male); female & $0.072^{*}$ & & $0.236^{* * *}$ & $0.186^{* * *}$ & $0.165^{* * *}$ \\
\hline $\begin{array}{l}\text { Size of the Child at birth (base: large } \\
\text { size) } \\
\quad \text { Average size }\end{array}$ & 0.021 & & -0.203 & -0.089 & -0.016 \\
\hline Small size & -0.127 & & $-0.405^{* * *}$ & $-0.313^{* * *}$ & $-0.325^{* * *}$ \\
\hline Birth order & $0.128^{* * *}$ & & -0.052 & -0.028 & -0.043 \\
\hline Average birth-spacing & -0.003 & & -0.002 & -0.001 & -0.003 \\
\hline \multicolumn{6}{|l|}{ Mother-level covariates } \\
\hline Mother's years since first marriage & $-0.053^{* * *}$ & & $0.098^{* * *}$ & 0.016 & 0.002 \\
\hline Mother's age at childbirth & $0.024^{* * *}$ & & $-0.122^{* * *}$ & -0.009 & 0.018 \\
\hline $\begin{array}{l}\text { Place of delivery of child } \\
\text { (base: home delivery) } \\
\text { Institutional delivery }\end{array}$ & $-0.163^{* * *}$ & & -0.081 & 0.035 & 0.032 \\
\hline Mother's education in years & -0.003 & & $-0.028^{* * *}$ & 0.002 & 0.002 \\
\hline Women's decision-making index & $0.114^{* * *}$ & & $0.251^{* * *}$ & -0.004 & $0.166^{*}$ \\
\hline Mothers BMI: $\geq 18.5$ (base $=18.5$ ) & $0.428^{*}$ & & -0.045 & 0.220 & $0.514^{*}$ \\
\hline $\begin{array}{l}\text { Duration of breastfeeding: } \\
\text { (base: less than } 6 \text { months) } \\
\text { More than } 6 \text { months }\end{array}$ & $-0.515^{* * *}$ & & $-0.746^{* * *}$ & $-0.563^{* * *}$ & $-0.544^{* * *}$ \\
\hline $\begin{array}{l}\text { Composite index of infant and child } \\
\text { feeding practices }\end{array}$ & $0.030^{* *}$ & & -0.004 & -0.011 & -0.008 \\
\hline \multicolumn{6}{|l|}{ Household-level covariates } \\
\hline $\begin{array}{l}\text { Wealth index: (base: poorest quintile) } \\
\text { 2nd quintile }\end{array}$ & $-0.256^{* * *}$ & & $-0.790^{* * *}$ & -0.069 & -0.063 \\
\hline Middle quintile & 0.091 & & 0.434 & 0.046 & 0.011 \\
\hline 4th quintile & $0.310^{* * *}$ & & $0.602^{*}$ & -0.023 & $0.042^{*}$ \\
\hline Richest quintile & 0.067 & & $1.596^{* * *}$ & -0.015 & $0.119^{* *}$ \\
\hline $\begin{array}{l}\text { Composite healthcare utilization index } \\
\text { (base: poor utilization level) } \\
\quad \text { Moderate utilization level }\end{array}$ & $0.125^{* *}$ & & 0.065 & 0.090 & $0.146^{* * *}$ \\
\hline Good utilization level & $0.359^{* * *}$ & & 0.035 & 0.100 & $0.226^{* * *}$ \\
\hline \multicolumn{6}{|l|}{ Community-level covariates } \\
\hline $\begin{array}{l}\text { Distance to health facility } \\
\text { (base: facility faraway); } \\
\text { health facility nearby }\end{array}$ & $-0.186^{* * *}$ & & 0.256 & -0.101 & $-0.131^{*}$ \\
\hline $\begin{array}{l}\text { Water source (base: piped water) not } \\
\text { piped water Region: Lower Egypt } \\
\text { urban (urban governorates: 1) }\end{array}$ & $\begin{array}{l}-0.580^{* * *} \\
-0.493^{* * *}\end{array}$ & & $\begin{array}{l}0.502 * * * \\
-1.000^{* *}\end{array}$ & $\begin{array}{c}0.080 \\
-0.707^{* * *}\end{array}$ & 0.008 \\
\hline Lower Egypt rural & $-0.964^{* * *}$ & & $3.415^{* * *}$ & $-0.656^{* *}$ & \\
\hline Upper Egypt urban & $-0.514^{* * *}$ & & $3.107^{* * *}$ & -0.002 & \\
\hline Upper Egypt rural & $-0.914^{* * *}$ & & $2.738^{* *}$ & $-0.505^{* *}$ & \\
\hline Frontier governorates & $-0.428^{* * *}$ & & 0.874 & $-0.464^{* * *}$ & \\
\hline Place of residence (base: urban) rural & 0.182 & & -1.210 & 0.260 & 0.074 \\
\hline Constant & -0.310 & & $1.926^{* *}$ & 0.644 & -0.534 \\
\hline $\mathbf{N}$ & 8505 & 8505 & 8505 & 8505 & 8505 \\
\hline
\end{tabular}

Note: Dependent variable: height-for-age $z$-scores (standardized).

${ }^{* * *} P<0.01,{ }^{* *} P<0.05,{ }^{*} P<0.1$. 
(about $25 \%$ ) is explained by clustering at the community level. Typically, if undernutrition is purely an individual risk for a particular child, most of the observed variance will be accounted at the individual level. Table 3 clearly indicates that while about $60 \%$ of the variance can be explained by clustering of malnourished children within a household, suggesting a strong intrahousehold or intrasibling correlation in undernutrition risks, a significant proportion of undernourished children tend to reside within the same community, most likely backward and hard-to-reach areas. Such strong neighborhood effects, brought to the fore by the multilevel models used here, point to a regional and geographic targeting of nutritional programmes among backward regions and/or communities, possibly augmenting the individual-centric efforts that are currently on across the developing countries.

3.4. Risk-Factors of Long-Term Undernutrition among Children in Egypt: Towards Profiling the Vulnerable Populations. We have discussed above the significant determinants of long-term undernutrition among children and observed the clustering of the incidence of average stunting at different levels of observation in the EDHS data. Following the second objective, we may now turn towards understanding the relative risk and vulnerability to suffer from adverse nutritional outcomes resting on the analytical framework exposed earlier.

A standard way of analyzing such relative-risk assessments is through limited dependent variables models, which involves alternative functional forms of regression with categorical (often binary) dependent variables. Logistic regression is one of the most extensively used technique for analyzing binary outcomes and identifying the "odds" or chances of occurrence of the "success" for different (categories of) the predictor variables (for details refer [22, 23]). Using similar set of covariates as in the preceding section, we regress the binary outcome variable for stunting (child stunted: 1; otherwise: 0 ) using a logistic functional form.

Following earlier attempts by researchers studying similar phenomena [24-26], we employ random-effect logistic regression models to account for the clustering nature of observations in the data, as elaborated earlier. We specified random effects for mothers, primary sampling units (community), and geographic regions. Fixed-effect specifications, were also run (not reported) as competing models, and suitability of the two forms assessed through sensitivity tests of our findings to the choice of models. It is believed that while random-effect models have the advantage of being more efficient, the latter is often considered to be less biased as all the observed and unobserved characteristics of the state that are time-constant are accounted for $[24,27]$. We find random-effect model to be a better choice over the fixed-effect form as indicated by generalized Hausman tests, and the parameter estimates are reported in Table 4. We also attempted a gradual approach to introduce variables at different levels (child, mother, household, and community), with appropriate ransom effects, but following likelihood ratio (LR) tests lead to infer that no substantial gains are made in such an approach. Hence, we
TABLE 3: Random coefficients, intraclass correlation and variance decomposition.

\begin{tabular}{|c|c|c|}
\hline Parameters & Null model & Full model \\
\hline & \multicolumn{2}{|c|}{ Random effects } \\
\hline$\sigma^{2}$ (region) & 0.054 & 0.013 \\
\hline SE & 0.037 & 0.217 \\
\hline $\begin{array}{l}\text { Proportions of overall } \\
\text { (null model) explained } \\
\text { by model covariates }\end{array}$ & & 75.730 \\
\hline$\sigma^{2}$ (cluster) & 0.538 & 0.479 \\
\hline SE & 0.054 & 0.696 \\
\hline $\begin{array}{l}\text { Proportions of overall } \\
\text { (null model) explained } \\
\text { by model covariates }\end{array}$ & & 10.932 \\
\hline$\sigma^{2}$ (household) & 0.397 & 0.270 \\
\hline SE & 0.197 & 1.078 \\
\hline $\begin{array}{l}\text { Proportions of overall } \\
\text { (null model) explained } \\
\text { by model covariates }\end{array}$ & & 31.916 \\
\hline$\sigma^{2}$ (mother) & 1.732 & 1.177 \\
\hline SE & 0.200 & 1.932 \\
\hline $\begin{array}{l}\text { Proportions of overall } \\
\text { (null model) explained } \\
\text { by model covariates }\end{array}$ & & 32.023 \\
\hline Residual $^{2}$ & 0.540 & 0.457 \\
\hline SE & 0.012 & 0.500 \\
\hline \multicolumn{3}{|c|}{ Intraclass correlation } \\
\hline$\Psi$ (region) & 0.017 & 0.005 \\
\hline$\Psi$ (cluster) & 0.220 & 0.197 \\
\hline$\Psi$ (household) & 0.851 & 0.714 \\
\hline$\Psi$ (mother) & 1.520 & 1.253 \\
\hline \multicolumn{3}{|c|}{ Variance decomposition } \\
\hline Region & 2.0 & 0.7 \\
\hline Cluster & 19.8 & 24.7 \\
\hline Household & 14.6 & 13.9 \\
\hline Mother & 63.7 & 60.7 \\
\hline
\end{tabular}

comment on the results of the full model as represented in Table 4 .

Generally, the results are largely similar to the findings from the earlier exercise, with the major determinants of child undernutrition constituting the most important riskfactors. However, in view of the finding of the predominance of community level factors in explaining the observed heterogeneity of the models, results should be interpreted with caution since the number of observations in the "reference" category can influence substantially the outcome variables (i.e., occurrence of stunting).

Thus, apart from the predictors (or categories of predictors) as discussed in the earlier section-males, low-birth weight babies, being breastfed for longer duration, children from households, and/or communities not having access to piped water are more prone or vulnerable to suffer from chronic undernutrition. A positive and significant wealth 
TABLE 4: Relative risk and vulnerability to long-term undernutrition among children: results of random-effect logistic regression model.

\begin{tabular}{|c|c|c|c|}
\hline Predictors & Odds ratio & SE & 95\% Conf. interval \\
\hline \multicolumn{4}{|l|}{ Child-level covariates } \\
\hline Age of the child (in months) & $0.994^{*}$ & -0.003 & $0.988,1.000$ \\
\hline Sex of the child (base: male) female & $0.812^{* *}$ & -0.042 & $0.734,0.898$ \\
\hline $\begin{array}{l}\text { Size of the child at birth (Base: large } \\
\text { size) }\end{array}$ & $1.555^{* *}$ & -0.222 & $1.175,2.059$ \\
\hline \multicolumn{4}{|l|}{ Average size } \\
\hline Small size & $1.579^{* *}$ & -0.252 & $1.155,2.160$ \\
\hline Birth order & $0.801^{* *}$ & -0.027 & $0.750,0.855$ \\
\hline Average birth-spacing & $1.009^{* *}$ & -0.002 & $1.004,1.014$ \\
\hline \multicolumn{4}{|l|}{ Mother-level covariates } \\
\hline Mother's years since first marriage & $1.031^{*}$ & -0.015 & $1.002,1.061$ \\
\hline Mother's age at childbirth & $1.022^{+}$ & -0.013 & $0.997,1.047$ \\
\hline $\begin{array}{l}\text { Place of delivery of child (base: home } \\
\text { delivery) institutional delivery }\end{array}$ & 1.11 & 1.11 & $0.974,1.264$ \\
\hline Mother's education in years & 1.002 & -0.006 & $0.991,1.012$ \\
\hline Women's decision-making index & 0.961 & -0.036 & $0.892,1.034$ \\
\hline Mother's BMI: $\geq 18.5$ (base $=18.5)$ & 0.635 & -0.194 & $0.349,1.157$ \\
\hline $\begin{array}{l}\text { Duration of breastfeeding: } \\
\text { (base: less than } 6 \text { months); } \\
\text { more than } 6 \text { months }\end{array}$ & $1.878^{* *}$ & -0.162 & $1.586,2.224$ \\
\hline $\begin{array}{l}\text { Composite index of infant and child } \\
\text { feeding practices }\end{array}$ & $0.965^{*}$ & -0.016 & $0.934,0.997$ \\
\hline \multicolumn{4}{|l|}{ Household-level covariates } \\
\hline $\begin{array}{l}\text { Wealth index: (base: poorest quintile) } \\
\text { 2nd quintile }\end{array}$ & $1.428^{* *}$ & -0.162 & $1.222,1.669$ \\
\hline Middle quintile & $0.806^{*}$ & -0.072 & $0.677,0.960$ \\
\hline 4th quintile & $0.626^{* *}$ & -0.066 & $0.508,0.770$ \\
\hline Richest quintile & $0.805^{+}$ & -0.098 & $0.633,1.023$ \\
\hline $\begin{array}{l}\text { Composite healthcare utilization index } \\
\text { (base: poor utilization level) } \\
\quad \text { Moderate utilization level }\end{array}$ & 1.111 & -0.078 & $0.969,1.275$ \\
\hline Good utilization level & $0.750^{* *}$ & -0.083 & $0.603,0.932$ \\
\hline \multicolumn{4}{|l|}{ Community-level covariates } \\
\hline $\begin{array}{l}\text { Distance to health facility } \\
\text { (base: facility faraway); } \\
\text { health facility nearby }\end{array}$ & $1.482^{* *}$ & -0.102 & $1.295,1.697$ \\
\hline $\begin{array}{l}\text { Water source (base: piped water); non } \\
\text { piped water }\end{array}$ & $1.831^{* *}$ & -0.132 & $1.589,2.110$ \\
\hline Place of residence (base: urban); rural & 1.053 & -0.267 & $0.640,1.733$ \\
\hline Constant & $0.064^{* *}$ & -0.032 & $0.024,0.172$ \\
\hline $\mathrm{N}$ & & 8505 & \\
\hline
\end{tabular}

Note: whether child stunted (1: Yes; 0: No).

${ }^{+} P<.10,{ }^{*} P<.05$, and ${ }^{* *} P<.01$.

effect as well as benefits accruing from better healthcare utilization and feeding/care practices of young children lead to a lower probability of being stunted.

\section{Conclusion}

This paper attempts to an understanding of the determinants and individual vulnerabilities to long-term undernutrition among children, a sublime indicator of well-being of a society as well as an important Millennium Development Goal, based on recent household survey data from Egypt. Apart from identifying the clustering across demographic and socioeconomic correlates resting on an analytical framework, we identify the significant determinants of adverse nutritional outcomes and relative risk factor or vulnerabilities to the same. Interestingly, and differing from comparative 
findings from other developing countries, we do not find any significant association of mothers' education and to an extent, higher decision-making power among women with better nutritional status of children, measured in terms of low height-for-age (or stunting). However, the findings reiterate the importance and positive effects of economic status and living standards on the one hand and better access to and awareness of health-seeking behavior and infant and young children care and feeding (IYCF) practices, as being associated with significantly lower risks of undernutrition. We also identify strong neighborhood effects in explaining the clustering of undernutrition across children, with stunted children more likely to be coresiding in certain spatial communities such as backward hamlets. This has important policy implications: targeting might be required at macrolevel as well with programme attention concentrated on backward and otherwise vulnerable communities, in order to influence household food security and balanced diet being made available to children in these communities, which can lead to significant improvements in the nutritional outcomes in Egypt. Although, our analyses could have revealed more if we could incorporate other macrolevel parameters that can more distinctly segregate communities or clusters in terms of developmental indicators and then test the macrolevel association, the complimentary micro-level investigation brings to the fore the importance of contextual effects that should be considered to adequately address vulnerabilities at the individual or household level.

\section{References}

[1] F. El-Zanaty and A. Way, Egypt Demographic and Health Survey-2008, Ministry of Health, El-Zanaty and Associates and Macro International, Cairo, Egypt, 2009.

[2] FAO, Country Nutrition Profile: Egypt, FAO, Rome, Italy, 2003.

[3] UNICEF (United Nations Children's Fund), Strategy for Improved Nutrition of Children and Women in Developing Countries, UNICEF, New York, NY, USA, 1990.

[4] M. Gragnolati, "Children's growth and poverty in rural guatemala," World Bank Policy Research Working Paper no. 2193, September 1999.

[5] M. A. M. Gragnolati, "Nonlinear effects of altitude on child growth in peru: a multilevel analysis," WPS3823, The World Bank, 2006.

[6] N. Rice and A. Jones, Multilevel Models and Health Economics, Center for Health Economics Discussion Paper, University of York, 1997.

[7] J. B. Bingenheimer and S. W. Raudenbush, "Statistical and substantive inferences in public health: issues in the application of multilevel models," Annual Review of Public Health, vol. 25, pp. 53-78, 2004.

[8] G. Angeles, D. K. Guilkey, and T. A. Mroz, "The impact of community level variables on individual level outcomes: theoretical results and demographic applications," WP-02-50, Carolina Population Center, University of North Carolina at Chapel Hill, 2002, http://pdf.usaid.gov/pdf_docs/PNACQ362 .pdf.
[9] World Health Organization Multicenter Growth Reference Study Group, WHO Child Growth Standards: Length/Heightfor-Age, Weight-for-Age, Weight-for-Length, Weight-for-Height and Body Mass Index-for-Age-Methods and Development, World Health Organization, Geneva, Switzerland, 2006.

[10] IIPS, "National Family Health Survey 2005-2006 (NFHS-3)," India Report, Volume I, International Institute for Population Sciences, Mumbai and ORC Macro, 2007.

[11] F. El-Zanaty and A. Way, Egypt Demographic and Health Survey-2005, Ministry of Health, El-Zanaty and Associates and Macro International, Cairo, Egypt, 2006.

[12] E. Geerlings, L. Albrechtsen, and J. Rushton, "Highly pathogenic avian influenza: a rapid assessment of the socioeconomic impact on vulnerable households in Egypt," FAO/WFP-Joint Project, Rome, Italy, 2007.

[13] M. Gragnolati and A. Marini, "Malnutrition and poverty in Guatemala," Policy Research Working Paper \# 2967, The World Bank, Washington, DC, USA, 2003.

[14] A. Wagstaff and N. Watanabe, "Socioeconomic Inequalities in Child Malnutrition in the Developing World," Policy Research Working Paper WPS 2434, Development Research Group, The World Bank, Washington, DC, USA, 2000.

[15] P. Svedberg, "Child malnutrition in India and China," in 2020 Focus Brief on the World's Poor and Hungry People, 2007.

[16] S. Mazumdar, "Child malnutrition in India: the impact of poverty and inequality," Unpublished Working Paper, 2008.

[17] L. C. Smith and L. J. Haddad, "Explaining child malnutrition in developing countries: a cross-country analysis," FCND Discussion Paper \# 60, Food Consumption and Nutrition Division, International Food Policy Research Institute (IFPRI), Washington, DC, USA, 1999.

[18] L. C. Smith, U. Ramakrishnan, A. Ndiaye, L. J. Haddad, and R. Martorell, "The importance of women's status for child nutrition in developing countries," Research Report no. 131, International Food Policy Research Institute, Washington, DC, USA, 2003, http://www.ifpri.org/sites/default/files/ publications/rr131.pdf.

[19] T. M. Ruel and P. Menon, "Creating a child feeding index using the Demographic and Health Surveys: an example from Latin America," FCND Discussion Paper no. 130, Food Consumption and Nutrition Division, International Food Policy Research Institute, Washington, DC, USA, 2002.

[20] S. O. Rutstein and K. Johnson, "The DHS wealth index," DHS Comparative Reports \# 6, ORC Macro, Calverton, Md, USA, 2004.

[21] C. Baum, An Introduction to Modern Econometrics Using STATA, STATA Press, College Station, Tes, USA, 2006.

[22] R. Retherford and M. K. Choe, Statistical Models for Causal Analysis, Wiley-Eastern, New Delhi, 1993.

[23] G. S. Maddala, Limited Dependent and Qualitative Variables in Econometrics, Cambridge University Press, Cambridge, UK, 1983.

[24] M. A. Subramanyam, I. Kawachi, L. F. Berkman, and S. V. Subramanian, "Is economic growth associated with reduction in child undernutrition in India?" PLoS Medicine, vol. 8, no. 3, Article ID e1000424, 2011, http://www.plosmedicine.org/ article/info:doi/10.1371/journal.pmed.1000424.

[25] M. M. M. Maia, M. A. Fausto, E. L. M. Vieira, M. L. F. N. Benetton, and M. Carneiro, "The prevalence of malnutrition and its risk factors in children attending outpatient clinics in the city of Manaus, Amazonas, Brazil," Archivos Latinoamericanos de Nutricion, vol. 58, no. 3, pp. 234-240, 2008, http:// www.scielo.org.ve/pdf/alan/v58n3/art04.pdf. 
[26] C. A. Santos, R. L. Fiaccone, N. F. Oliviera et al., "Estimating adjusted prevalence ratio in clustered cross-sectional epidemiological data," BMC Medical Research Methodology, vol. 8, article 80, 2008, http://www.biomedcentral.com/content/ pdf/1471-2288-8-80.pdf.

[27] S. Rabe-Hesketh and A. Skrondal, Multilevel and Longitudinal Modeling Using Stata, STATA Press, College Station, Tex, USA, 2005. 


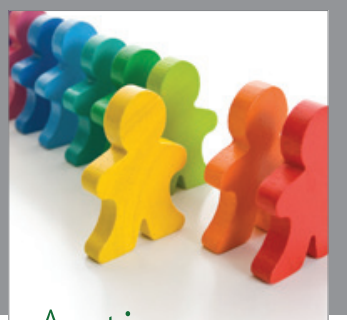

Autism

Research and Treatment
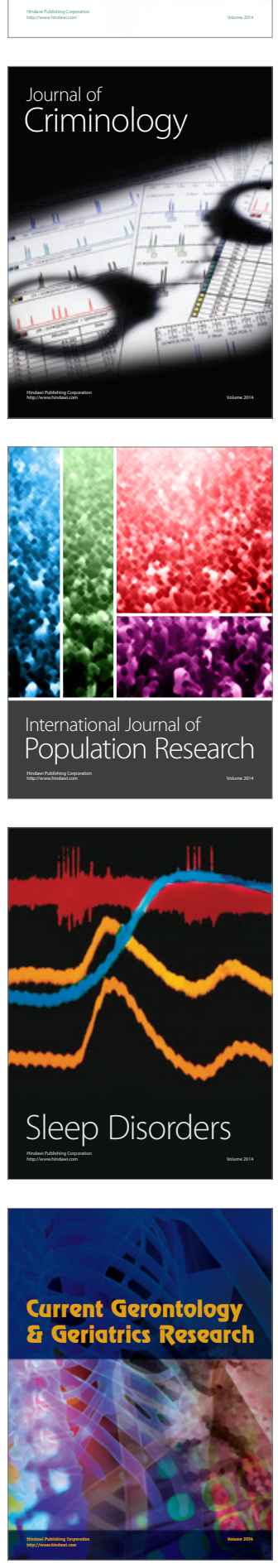
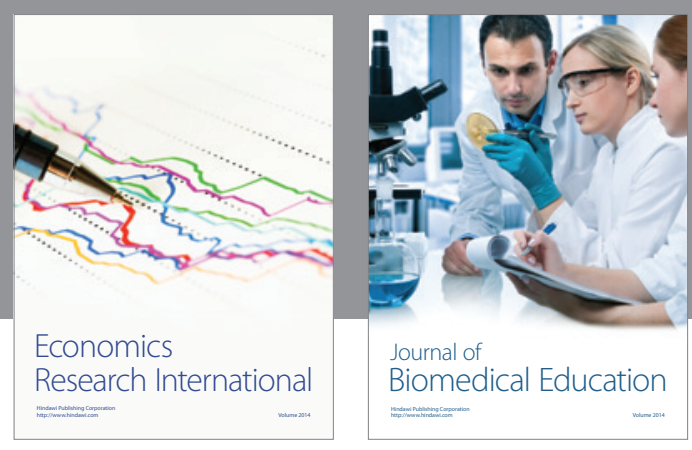

Journal of

Biomedical Education

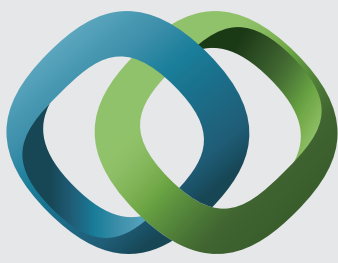

\section{Hindawi}

Submit your manuscripts at

http://www.hindawi.com
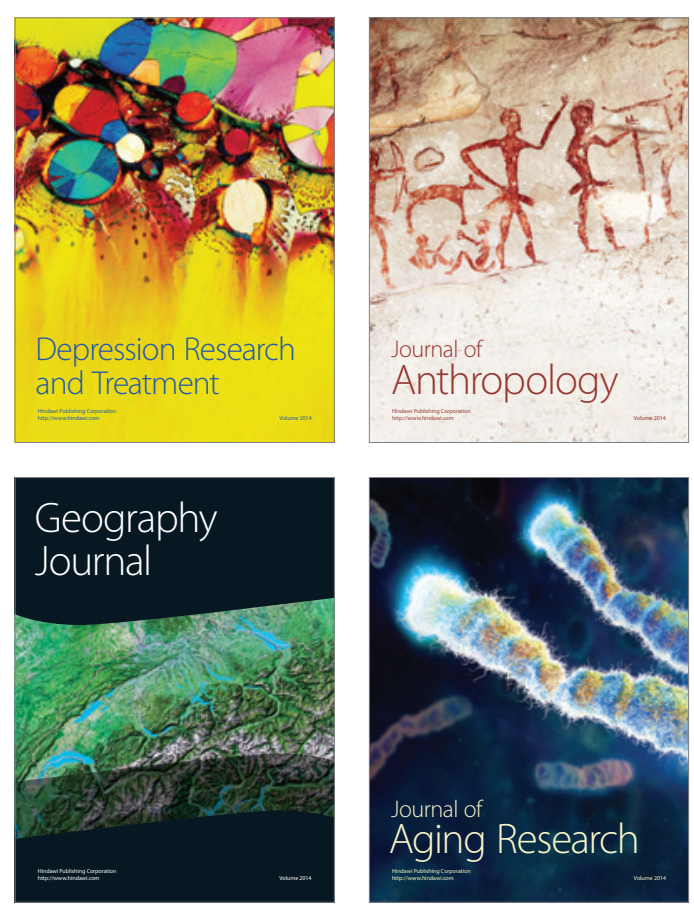

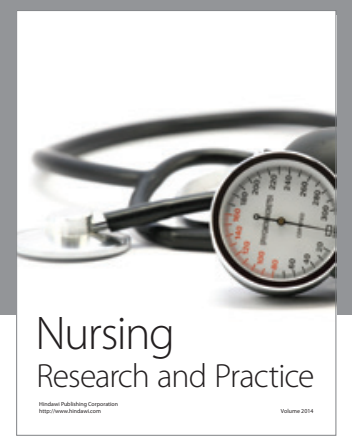

Nursing

Research and Practice

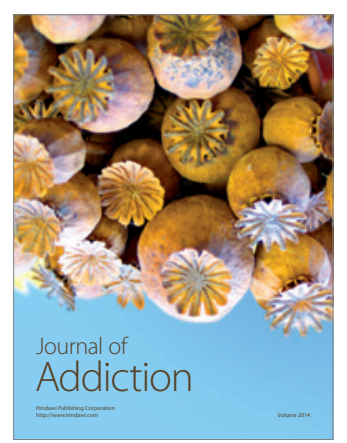

Child Development

Research

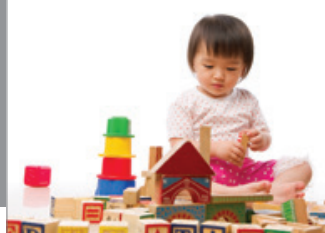

迥
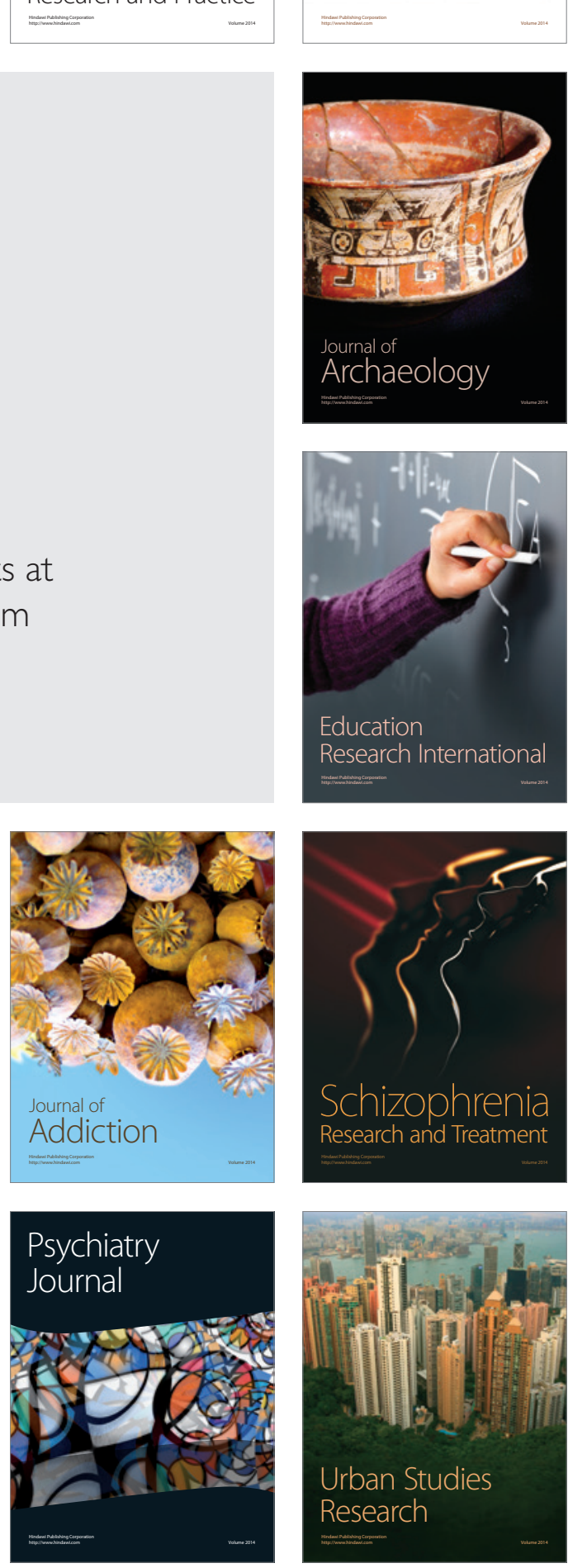